\title{
Risk Perception of Nuclear Power Plants Among University Students in Northeast Asia After the Fukushima Nuclear Disaster
}

\author{
Marco Chi Fong Ieong, BS ${ }^{1^{*}}$, Jung-Chun Ho, PhD $^{1^{*} \text {, }}$ \\ Patricia Chiao-Tze Lee, PhD $^{2}$, Tomiko Hokama, PhD $^{3}$, \\ Tsugiko Gima, $\mathrm{PhD}^{3}$, Lingling Luo, $\mathrm{PhD}^{4}$, \\ Myongsei Sohn, MD, PhD ${ }^{5}$, So Yoon Kim, MD, PhD ${ }^{5}$, \\ Shu-Fen Kao, $\mathbf{P h D}^{6}$, Wanhwa Annie Hsieh, $\mathbf{P h D}^{7}$, \\ Hung-Lun Chang, BS ${ }^{1}$, and Peter Wu-Shou Chang, MD, PH, ScD ${ }^{1,8}$
}

\begin{abstract}
To examine the perception of nuclear energy risks among Asian university students following the Fukushima nuclear disaster, a standardized questionnaire survey was conducted since July 2011 after the Fukushima disaster. A total of 1814 respondents from 18 universities in China, Japan, Korea, and Taiwan participated in this survey. It showed that students with the following characteristics had a higher preference for "a clear schedule to phase out nuclear power plant (NPP)": females (adjusted odds ratio $[\mathrm{aOR}]=1.84,95 \%$ confidence interval $[\mathrm{CI}]=1.44-2.34$ ), in Japan $(\mathrm{aOR}=2.81,95 \% \mathrm{CI}=2.02-3.90)$, in China $(\mathrm{aOR}=1.48,95 \% \mathrm{CI}=1.04-2.09)$, and with perceived relative risks of cancer incidence greaterthan 1 ( $\mathrm{aOR}=1.42,95 \% \mathrm{CI}=1.07-1.88)$. "If nuclear energy were phased out," the opinions on potential electricity shortage were as follows: Japan, aOR $=0.53,95 \% \mathrm{CI}=0.40-0.69$; China, aOR $=2.46,95 \% \mathrm{CI}=1.75-3.45$; and associated with academic majors (science/technology, $\mathrm{aOR}=0.43,95 \% \mathrm{CI}=0.31-0.59$; medicine/health science, aOR $=0.64,95 \% \mathrm{CI}=0.49-0.84)$. The results carried essential messages for nuclear energy policy in East Asia.
\end{abstract}

\section{Keywords}

Fukushima, Northeast Asia, nuclear energy, risk perception, university student

\footnotetext{
*Authors with equal contribution

${ }^{1}$ Taipei Medical University, Taipei, Taiwan

${ }^{2}$ Griffith University, Gold Coast, Queensland, Australia

${ }^{3}$ University of the Ryukyus, Nishihara, Okinawa, Japan

${ }^{4}$ School of Humanities and Law, Northeastern University, Shenyang, China

${ }^{5}$ Yonsei University, Seoul, Korea

${ }^{6}$ Fo Guang University, Yilan, Taiwan

${ }^{7}$ Tzu Chi University, Hwalian, Taiwan

${ }^{8}$ Taipei Hospital, MOHW, New Taipei City, Taiwan

Corresponding Author:

Peter Wu-Shou Chang, College of Public Health and Nutrition, Taipei Medical University, 250 Wushin Street, Taipei,

Taiwan

Email: peter.chang3@gmail.com
} 


\section{Introduction}

The usage of nuclear energy has been increasing over the past 4 decades, from less than 100 total terawatt hours (TWh) in 16 countries in 1971, to more than $2500 \mathrm{TWh}$ in 31 countries in 2011. ${ }^{1,2}$ More specifically, in Northeast Asia, nuclear energy provided $1.8 \%, 18.1 \%, 34.6 \%$, and $19 \%$ of electricity supply in 2011 in China, Japan, Korea, and Taiwan, respectively. ${ }^{3}$ However, concerns about nuclear energy safety have been raised in the national agenda for many countries with sizeable nuclear industries, which are likely to affect the whole nuclear industry worldwide for decades. Such concerns have in part been fueled by serious nuclear disasters, such as the nuclear accident on Three Mile Island in 1979, Chernobyl in 1986, and Fukushima in 2011, which have caused various degrees of economic, environmental, physical, and psychological damages at regional, national and international levels.

After the Three Miles Island nuclear accident in the United States in 1979, a risk perception model on major technologies and human activities was proposed by Slovic et al. ${ }^{4}$ In their studies, nuclear power was rated as the highest among several major common risks rated by the college students and the women at that time. This was because of the fact that nuclear reactor accidents, radioactive waste, and fallout from nuclear weapons testing were considered as less voluntary, more catastrophic, higher in dread, more likely to be fatal, less controllable, and therefore, contributed to higher perceived risks. On the other hand, nuclear power was ranked 8th by the business and professional members and 20th by the experts. ${ }^{5,6}$ Apparently, the perceived risks toward nuclear energy varied significantly between different groups in the society.

In March 2011, the Fukushima earthquake considerably damaged the Daiichi nuclear power plants (NPPs) and triggered a tremendous nuclear disaster, with more than 200000 citizens evacuated more than $20 \mathrm{~km}$ away from the damaged plants. The incident was soon rated as a level 7 (major accident) on the International Nuclear and Radiological Event Scale of the International Atomic Energy Agency, which represents the highest rating on that scale for which there had only been one historical precedent with the Chernobyl disaster 25 years ago. ${ }^{7}$ Although nuclear energy has been developed in Japan and supported by government and industries for decades, NPPs have consistently been perceived as a high-risk business, with one study showing that nuclear risk had been ranked consistently high during the past 25 years. ${ }^{8}$ On the other hand, a recent study in China showed that the public acceptance of nuclear power was generally not high among those near an NPP in Jiangsu Province. ${ }^{9}$ The public concerns about nuclear energy's impact are widespread, and the distance from an NPP is one of the important factors to the knowledge and attitude toward nuclear power. A Korean study after the Fukushima accident also revealed that one of the most important issues after the accident was its socioeconomic damage caused by stigma, which in turn is caused by misunderstanding of the risks imposed. ${ }^{10}$

In Taiwan, a study in 1999 evaluating the communities neighboring the first and second NPPs revealed that the perceived risk by the local residents on nuclear power was relatively higher than those of the employees of the plant operators and their families. ${ }^{11}$ A recent survey in Taiwan conducted right before the Fukushima accident showed that the respondents lived near the second NPP opposed it and rejected the compensation payment from its operator, the Taiwan Electric Power Company, to continue the operation. The reason was that they regarded NPP as an extremely high-risk facility. ${ }^{12}$ A nationwide survey in Taiwan right after the 2011 Fukushima disaster revealed that $56 \%$ of the respondents opposed a planned new NPP, with several factors as the determinants, including females, residence near the planned site, distrust of safety management, and the emergency planning of the NPP. ${ }^{13}$

Many sociological researches argued that different communities reacted differently to the same risk event. ${ }^{14}$ The present study aimed to understand the perception of university students toward nuclear operation after the Fukushima nuclear incident and to identify determinants such as age, gender, academic majors, and so on, that may be associated with the perception and 


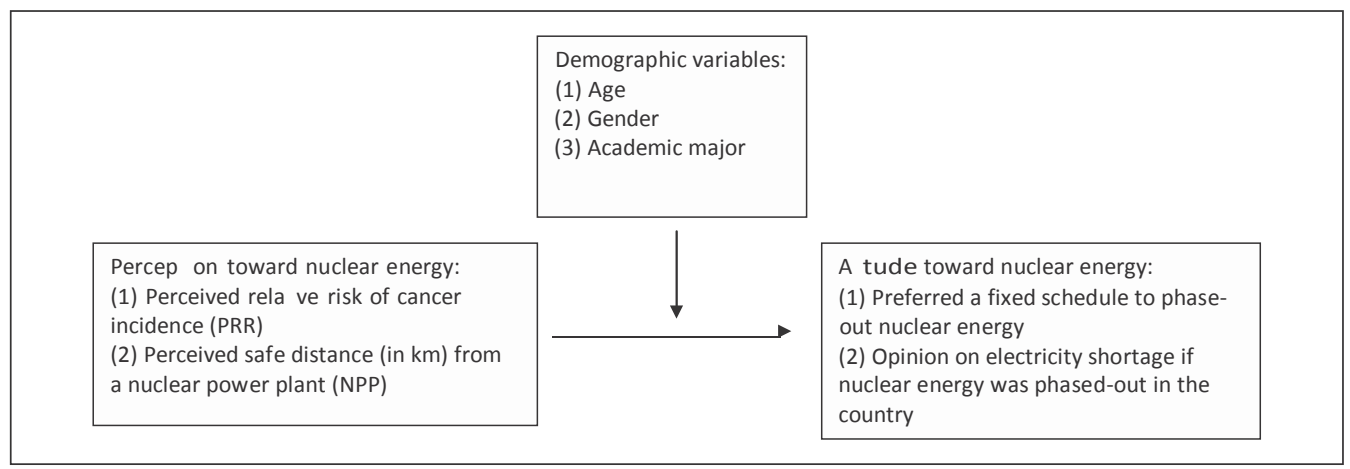

Figure 1. Conceptual framework of the study.

attitude toward nuclear energy (Figure 1). University students from within the region living in close proximity to the hypocenter of the nuclear accident were chosen as the study population as these may represent the mainstream of young populations in these areas and shared similar impacts.

\section{Method}

\section{Enrollment of Participants and Data Collection}

An invitation for joining the international comparative study was sent to more than 20 partner universities in Northeast Asia in July 2011. A total of 18 universities responded to the survey, including the universities at Shenyang in China, Ryukyu in Japan, Seoul in Korea, and several cities in Taiwan.

The academic major of the respondents in the university was recorded, while a minimal number of 50 university-registered students with similar academic major were required to join the survey conducted in the class. The invited instructors in the universities distributed the questionnaire in the designated classrooms after an explanation of the study was given, but were not allowed to guide the respondents or intervene. The respondents were instructed to respond individually and assured of the anonymity of responses and the fact that their results would not affect their performance in the specific study course. In addition, they were encouraged to answer all items in the questionnaires and adequate time, usually 30 minutes, was allotted. The questionnaires were then collected and centralized for data analysis in Taipei, while the University of Ryukyu built their own database with the same standardized procedures as that in Taiwan. The study was conducted starting from July and all questionnaires were collected before the end of December 2011. The study received approval from the institutional review board of Taipei Medical University in Taiwan (TMU-JIRB-201109002).

\section{Questionnaire Development and Standardization}

The structured self-reported questionnaire included demographic information, such as gender, age, academic major, and residential area, as well as the perception and attitude toward nuclear energy. Specifically, several questions about perception and attitude on nuclear energy were asked, including the following: (1) the perceived cancer cases per 1000 persons living within 30 $\mathrm{km}$ of an NPP, as compared with those living beyond $30 \mathrm{~km}$; perceived safe distance (in kilometers) from an NPP; (2) potential electricity shortage in their country if without nuclear energy; and (3) their opinions on whether a fixed schedule to phase out nuclear energy in their countries 
should be executed. A 5-point Likert-type scale (from strongly agree, agree, neutral, disagree, to strongly disagree) was used for most of the questions, whereas the opinions for a scheduled phase-out of nuclear energy was interpreted by time interval in years.

The structural questionnaire was based on a similar survey conducted in Taiwan in 1999.11 The instrument was modified and standardized in Japanese for students in Okinawa, translated using "Translation and Back-translation" by language experts. The instrument was in Simplified Chinese characters for students in China; in Traditional Chinese for students in Taiwan; and in English for students in Korea. The process was conducted by 2 independent multilingual researchers with guidance of language experts to ensure the consistency and accuracy of translation, and further reviewed by experts for its validity.

\section{Variables and Statistical Analyses}

Data were keyed in and double-checked for accuracy and quality. Questionnaires were considered invalid if the respondents had skipped 3 or more items of the questionnaire. "Perceived relative risk (PRR) of cancer incidences" was calculated based on 2 questions that represented a quotient of the respondents' estimated cancer cases per 1000 persons for living within and beyond $30 \mathrm{~km}$ of an NPP. A clear preferred schedule to phase out nuclear energy in the country or region was interpreted by time interval with "immediately," "1 to 5 years," "6 to 10 years," "after 10 years," "no schedule," and "no comment." These opinions were then categorized into "yes," "no," and "no comment," where "yes" included "immediately," "1 to 5 years," "6 to 10 years," and "after 10 years."

The data were analyzed using the SAS package version 9.2 (SAS Institute Inc, Cary, NC). The descriptive statistics (such as mean and percentage) were used to present the distribution of the demographics and the respondents' risk perceptions on nuclear energy. Two logistic regression models were performed independently to examine the association of the demographic variables and nuclear-related perception variables on the 2 dependent variables: preferred schedule to phase out NPP in their country and potential electricity shortage in their country if nuclear energy was phased out. Odds ratio (ORs) and 95\% confidence intervals (95\% CIs) were also calculated in the regression models.

\section{Results}

\section{Demographics}

Two universities in China, 1 in Korea, 1 in Japan, and 14 in Taiwan participated in the survey. A total of 1932 students responded to the questionnaires, among which 118 questionnaires were considered invalid because of incomplete response, giving 1814 (93.9\%) valid questionnaires for further analysis. The demographic information, such as age, gender, andacademic major were depicted in Table 1. The mean age (given as mean \pm standard deviation) of the 1814 respondents was $20.2 \pm 2.1$ years. The mean ages in the countries were $20.2 \pm 1.3,20.4 \pm 2.3,26.4 \pm 2.4$, and $19.6 \pm 1.3$ years from 300 respondents in China, 519 respondents in Japan, 77 respondents in Korea, and 918 respondents in Taiwan, respectively. The respondents in Korea were older than the others, as most of them were senior students in medical school. Female respondents represented $53.4 \%$ of all 1814 respondents, as well as $48.3 \%$ of respondents in China. The academic major was categorized as "art and literature," "science and technology," and "medicine and health science," according to their departments, where 38.5\% of the total respondents were from "art and literature," $22.3 \%$ were from "science and technology," and 39.2\% were from "medicine and health science." For students in China, 49.7\% studied in "art and literature" and the rest were in "science and technology"; none of them studied in "medicine and health sciences." For 
Table 1. Demographic Information of the Respondents With Their Perceptions and Attitude Toward Nuclear Energy.

\begin{tabular}{|c|c|c|c|c|c|}
\hline & $\begin{array}{c}\text { China } \\
(\mathrm{n}=300) ; \mathrm{n}(\%)\end{array}$ & $\begin{array}{c}\text { Japan } \\
(\mathrm{n}=519) ; \mathrm{n}(\%)\end{array}$ & $\begin{array}{c}\text { Korea } \\
(\mathrm{n}=77) ; \mathrm{n}(\%)\end{array}$ & $\begin{array}{c}\text { Taiwan } \\
(\mathrm{n}=918) ; \mathrm{n}(\%)\end{array}$ & $\begin{array}{c}\text { Total } \\
(\mathrm{N}=1814) ; \mathrm{n}(\%)\end{array}$ \\
\hline Age in years; mean (SD) & $20.2(1.3)$ & $20.4(2.3)$ & $26.4(2.4)$ & $19.6(1.3)$ & $20.2(2.1)$ \\
\hline \multicolumn{6}{|l|}{ Gender } \\
\hline Male & $155(51.7)$ & $242(46.6)$ & $31(40.3)$ & $417(45.4)$ & 845 (46.6) \\
\hline Female & $145(48.3)$ & $277(53.4)$ & $46(59.7)$ & $501(54.6)$ & $969(53.4)$ \\
\hline \multicolumn{6}{|l|}{ Academic major } \\
\hline Art and literature & $149(49.7)$ & $140(27.0)$ & $0(0.0)$ & 409 (44.6) & $698(38.5)$ \\
\hline Science and technology ${ }^{b}$ & $151(50.3)$ & $65(12.5)$ & $0(0.0)$ & $188(20.5)$ & $404(22.3)$ \\
\hline $\begin{array}{l}\text { Medicine and health } \\
\text { sciences }^{c}\end{array}$ & $0(0.0)$ & $314(60.5)$ & $77(100.0)$ & $321(34.9)$ & $712(39.2)$ \\
\hline \multicolumn{6}{|l|}{ PRR of cancer incidence ${ }^{d}$} \\
\hline$\leq 1$ & $51(17.0)$ & $142(27.3)$ & $21(27.3)$ & $173(18.9)$ & $387(21.3)$ \\
\hline$>1$ & $249(83.0)$ & 377 (72.7) & $56(72.7)$ & $745(81.1)$ & $1427(78.7)$ \\
\hline \multicolumn{6}{|c|}{ Perceived safe distance (in $\mathrm{km}$ ) from NPP } \\
\hline$<100$ & $43(14.7)$ & $75(15.4)$ & $11(15.1)$ & $500(57.1)$ & $629(36.4)$ \\
\hline$\geq 100$ & $250(85.3)$ & $413(84.6)$ & $62(84.9)$ & $375(42.9)$ & $1100(63.6)$ \\
\hline \multicolumn{6}{|c|}{ Potential electricity shortage in their country or region if nuclear energy was phased out } \\
\hline $\begin{array}{l}\text { Strongly agree and } \\
\text { agree }\end{array}$ & $214(71.3)$ & $201(38.8)$ & $47(61.0)$ & $511(56.5)$ & $973(54.1)$ \\
\hline $\begin{array}{l}\text { Strongly disagree, } \\
\text { disagree, and neutral }\end{array}$ & $86(28.7)$ & $317(61.2)$ & $30(39.0)$ & $393(43.5)$ & $826(45.9)$ \\
\hline \multicolumn{6}{|c|}{ Preferred schedule to phase out NPP in their country or region } \\
\hline Yes $^{\mathrm{e}}$ & $192(64.0)$ & $323(62.2)$ & $32(41.6)$ & $514(56.0)$ & $1061(58.5)$ \\
\hline No & $76(25.3)$ & $83(16.0)$ & $25(32.5)$ & $322(35.1)$ & $506(27.9)$ \\
\hline No comment & $32(10.7)$ & $113(21.8)$ & $20(25.9)$ & $82(8.9)$ & 247 (13.6) \\
\hline
\end{tabular}

Abbreviations: SD, standard deviation; PRR, perceived relative risk; NPP, nuclear power plant.

a"Art and literature" included art, literature, law, business management, economics, and tourism.

b"Science and technology" included civil engineering, computer system engineering, electronic engineering, and architecture.

"Medicine and health science" included medicine, nutrition and food science, publichealth, and nursing.

dPRR of cancer incidence $=$ estimated cancer incidences per 1000 persons living within versus beyond $30 \mathrm{~km}$ of an NPP.

e"Yes" included "Immediately," "1 to 5 years," "6 to 10 years," and "After 10 years."

students in Japan, $27.0 \%$ studied in "art and literature," $12.5 \%$ in "science and technology," and $60.5 \%$ in "medicine and health science." For students in Korea, all the responding students studied in "medicine and health science." For students in Taiwan, $44.6 \%$ of the respondents were from "art and literature," 20.5\% from "science and technology," and the remaining 34.9\% were from "medicine and health science."

\section{Perceptions and Attitude Toward Nuclear Energy}

The perceptions and attitude toward nuclear energy were expressed as the perceived relative risk (PRR) of cancer incidence, perceived safe distance from a NPP, potential electricity shortage if nuclear energy was phased out in the country or region, and the preferred clear schedule to phase out NPP in their country or region; all of which are presented in Table 1.

Concerning perceived excess cancer risk of living within $30 \mathrm{~km}$ of a NPP (PRR >1), 78.7\% of all the respondents perceived PRR $>1$, with $83.0 \%$ the respondents in China, $72.7 \%$ in Japan, $72.7 \%$ in Korea and $81.1 \%$ in Taiwan.

The average $( \pm 1$ SD) perceived safe distance from a NPP for all respondents was $273.5 \mathrm{~km}$ $( \pm 348.9)$, with $63.6 \%$ of respondents reporting a safe distance of greater than $100 \mathrm{~km}$. The proportion of respondents from China, Japan, and Korea who indicated a safe distance of greater 
Table 2. Analysis of the Associated Determinants With a Preference for "a Clear Schedule to Phase Out Nuclear Power Plant (NPP) in Their Country or Region" via Univariate and Multivariate Logistic Regression With Crude Odd Ratios (ORs) and Adjusted Odd Ratios (aOR), ${ }^{a}$ Respectively.

\begin{tabular}{|c|c|c|c|c|c|}
\hline \multirow[b]{2}{*}{ Dependent Variables } & \multirow[b]{2}{*}{ Total; n (\%) } & \multicolumn{4}{|c|}{$\begin{array}{l}\text { Preferred Schedule to Phase Out NPP in Their Country or } \\
\text { Region: Yes }{ }^{b} \text { Versus No }\end{array}$} \\
\hline & & Crude OR $(95 \% \mathrm{CI})$ & $P$ Value & Adjusted OR (95\% CI) & $P$ Value \\
\hline Age, mean (SD) & $20.2(2.1)$ & $1.00(0.95-1.05)$ & .831 & $1.04(0.97-1.12)$ & .299 \\
\hline \multicolumn{6}{|l|}{ Gender } \\
\hline Male & 845 (46.6) & 1 & & 1 & \\
\hline Female & $969(53.4)$ & $1.79(1.44-2.22)$ & $<.001$ & $1.84(1.44-2.34)$ & $<.001$ \\
\hline \multicolumn{6}{|l|}{ Country or Region } \\
\hline Taiwan & $918(50.6)$ & 1 & & 1 & \\
\hline Japan & $519(28.6)$ & $2.43(1.84-3.22)$ & $<.001$ & $2.81(2.02-3.90)$ & $<.001$ \\
\hline China & $300(16.6)$ & $1.58(1.17-2.13)$ & .002 & $1.48(1.04-2.09)$ & .027 \\
\hline Korea & $77(4.2)$ & $0.80(0.46-1.37)$ & .424 & $0.72(0.34-1.54)$ & .402 \\
\hline \multicolumn{6}{|l|}{ Academic major } \\
\hline Art and literature & $698(38.5)$ & 1 & & 1 & \\
\hline Science and technology ${ }^{d}$ & $404(22.2)$ & $0.73(0.55-0.97)$ & .031 & $0.88(0.63-1.21)$ & .424 \\
\hline Medicine and health sciences & $712(39.3)$ & $0.88(0.69-1.12)$ & .301 & $0.71(0.53-0.94)$ & .019 \\
\hline \multicolumn{6}{|c|}{ Perceived relative risk $(P R R)^{\mathrm{f}}$ of cancer incidence } \\
\hline$\leq 1$ & $338(19.2)$ & 1 & & 1 & \\
\hline$>1$ & $1427(80.8)$ & $1.38(1.07-1.79)$ & .013 & $1.42(1.07-1.88)$ & .016 \\
\hline \multicolumn{6}{|c|}{ Perceived safe distance (in km) from NPP } \\
\hline$<100$ & $629(36.4)$ & 1 & & 1 & \\
\hline$\geq 100$ & $1100(63.6)$ & $1.39(1.11-1.73)$ & .003 & $0.98(0.77-1.27)$ & .928 \\
\hline
\end{tabular}

${ }^{a}$ The factors adjusted, respectively, in the model are presented in the left column.

b"Yes" included "immediately," "1 to 5 years," "6 to 10 years," and "after 10 years."

"“Art and literature" included art, literature, law, business management, economics, and tourism.

d"Science and technology" included civil engineering, computer system engineering, electronic engineering, and architecture.

e"Medicine and health science" included medicine, nutrition and food science, public health, and nursing.

fPerceived relative risk (PRR) of cancer incidence = estimated cancer cases per 1000 person living within and beyond $30 \mathrm{~km}$ of a nuclear power plant.

than $100 \mathrm{~km}$ was $85.3 \%, 84.6 \%$, and $84.9 \%$, respectively. However, only $42.9 \%$ of those in Taiwan perceived a distance greater than $100 \mathrm{~km}$ from a NPP as the safe distance.

Overall, $54.1 \%$ of respondents perceived that electricity shortage might occur if nuclear energy was phased out, with such perception being held by $71.3 \%, 61.0 \%$, and $56.6 \%$ of respondents in China, Korea, and Taiwan, respectively, compared with only $38.8 \%$ in Japan.

Of all the respondents, $58.5 \%$ had a preferred schedule to phase out nuclear energy, while $27.9 \%$ did not have preferred schedule, and $13.6 \%$ of the total respondents opted for "no comment" to this question. In China, Japan, and Taiwan, there were more respondents $(64.0 \%, 62.2 \%$, and $56.0 \%$, respectively) who had preferred a clear schedule to phase out nuclear energy, while only $41.6 \%$ of the respondents in Korea favored a clear schedule.

\section{Determinants Associated With a Preference for a Clear Schedule to Phase Out Nuclear Power Plant}

The results of analysis of determinants associated with a preference for "a clear schedule to phase out nuclear power plants" via univariate and multivariate logistic regression are presented in Table 2. Age was not identified to associate with the preference to have a clear schedule to phase out NPP (via univariate logistic regression; $\mathrm{OR}=1.00,95 \% \mathrm{CI}=0.95-1.05$ ). Female students 
were shown to have a significantly higher preference than male students for a clear schedule to phase out NPPs $(\mathrm{OR}=1.79,95 \% \mathrm{CI}=1.44-2.22)$.

The respondents in Japan and China, compared with those in Taiwan, were shown to have a significantly higher preference for a clear schedule to phase out nuclear energy (OR $=2.43,95 \%$ $\mathrm{CI}=1.84-3.22$ and $\mathrm{OR}=1.58,95 \% \mathrm{CI}=1.17-2.13$, respectively). In contrast, the Korean respondents have a lower preference for phase out of NPP when compared with those in Taiwan, although the results were not statistically significant $(\mathrm{OR}=0.80,95 \% \mathrm{CI}=0.46-1.37)$.

Students with majors in "science and technology," as compared with those majoring in "art and literature," had a significantly lower preference ( $\mathrm{OR}=0.73,95 \% \mathrm{CI}=0.55-0.97)$. The same trend was shown for those studying "medicine and health sciences," but the result is not statistically significant $(\mathrm{OR}=0.88,95 \% \mathrm{CI}=0.69-1.12)$.

Those students who perceived excess cancer risks ( $\mathrm{PRR}>1$; $\mathrm{OR}=1.38,95 \% \mathrm{CI}=1.07-1.79$ ), as well as those perceived a safe distance of more than $100 \mathrm{~km}$ from a NPP (OR $=1.39,95 \% \mathrm{CI}$ $=1.11-1.73$ ) were shown to have a significantly higher preference to phase out the NPPs.

We further conducted multivariate logistic regression analysis and found that age (adjusted odds ratio $[\mathrm{aOR}]=1.04,95 \% \mathrm{CI}=0.97-1.12)$ and the perceived safe distance from a NPP $(\mathrm{aOR}$ $=0.98,95 \% \mathrm{CI}=0.77-1.27)$ were not statistically correlated with the preference of a clear schedule to phase out NPP.

Females $(\mathrm{aOR}=1.84,95 \% \mathrm{CI}=1.44-2.34)$, students in Japan $(\mathrm{aOR}=2.81,95 \% \mathrm{CI}=2.02$ 3.90), and students in China ( $\mathrm{aOR}=1.48,95 \% \mathrm{CI}=1.04-2.09$ ) were shown to have a significantly higher preference for a clear schedule to phase out NPPs than those in Taiwan.

Those with majors in "medicine and health science" $(\mathrm{aOR}=0.71,95 \% \mathrm{CI}=0.53-0.94)$ were shown to have a significantly higher preference for a clear schedule to phase out NPP as compared with those with majors in "art and literature."

For students who perceived higher excess cancer risk of living within $30 \mathrm{~km}$ from an NPP $(\mathrm{PRR}>1, \mathrm{aOR}=1.42,95 \% \mathrm{CI}=1.07-1.88)$ were shown to have a significant preference for a clear schedule to phase out nuclear energy.

\section{Determinants of Opinion of on Potential Electricity Shortage}

The determinants related to the opinion on potential electricity shortage were examined with the same statistical methods (Table 3). Age and gender were not statistically associated with the opinion on potential electricity shortage (age, $\mathrm{OR}=1.05,95 \% \mathrm{CI}=0.99-1.09$; gender, $\mathrm{OR}=$ $1.00,95 \% \mathrm{CI}=0.83-1.21$ ).

For those in Japan and China, the results showed statistically significant differences as compared with those in Taiwan. However, a lower proportion of students in Japan agreed with potential electricity shortage, as compared with those in Taiwan $(\mathrm{OR}=0.49,95 \% \mathrm{CI}=0.39-0.61)$, while a higher proportion of the respondents in China agreed with potential electricity shortage in the absence of nuclear energy $(\mathrm{OR}=1.92,95 \% \mathrm{CI}=1.44-2.54)$. However, the students from Korea did not show significant difference compared with those from Taiwan (OR $=1.21,95 \% \mathrm{CI}$ $=0.75-1.94$ ).

Students majoring in "art and literature" were compared with those in "science and technology" and "medicine and health science." Both of latter majors had a lower proportion of students agreeing with potential electricity shortage (science and technology, $\mathrm{OR}=0.69,95 \% \mathrm{CI}=0.54$ 0.89 ; medicine and health science, $\mathrm{OR}=0.59,95 \% \mathrm{CI}=0.48-0.73$ ).

In multivariate logistic regression, age and gender were shown to have a borderline significant association with the opinion on potential electricity shortage after adjustment of other determinants $(\mathrm{age}, \mathrm{aOR}=1.07,95 \% \mathrm{CI}=1.00-1.14$; gender, $\mathrm{aOR}=0.80,95 \% \mathrm{CI}=0.64-1.01)$. Respondents from Japan $(\mathrm{aOR}=0.53,95 \% \mathrm{CI}=0.40-0.69)$ were less likely and respondents 
Table 3. Analysis of the Determinants of Perceived Potential for Postnuclear Electricity Shortage in the Respondent's Country or Region via Univariate and Multivariate Logistic Regression With Crude Odd Ratios (ORs) and Adjusted Odds Ratios (aORs), ${ }^{a}$ Respectively.

Potential Electricity Shortage Without Nuclear Energy:

Agree $^{b}$ Versus Disagree

\begin{tabular}{lccccr}
\cline { 3 - 5 } Dependent Variables & Total; $n(\%)$ & $\begin{array}{c}\text { Crude OR } \\
(95 \% \text { CI })\end{array}$ & $P$ Value & $\begin{array}{c}\text { Adjusted OR } \\
(95 \% \text { CI })\end{array}$ & $P$ Value \\
\hline Age, mean (SD) & $20.2(2.1)$ & $1.05(0.99-1.09)$ & .071 & $1.07(1.00-1.14)$ & .051 \\
$\begin{array}{l}\text { Gender } \\
\quad \text { Male }\end{array}$ & & & & & \\
$\quad$ Female & $845(46.6)$ & 1 & & 1 & \\
Country or Region & $969(53.4)$ & $1.00(0.83-1.21)$ & .978 & $0.80(0.64-1.01)$ & .064 \\
$\quad$ Taiwan & $918(50.6)$ & 1 & & & \\
$\quad$ Japan & $519(28.6)$ & $0.49(0.39-0.61)$ & $<.001$ & $0.53(0.40-0.69)$ & $<.001$ \\
$\quad$ China & $300(16.6)$ & $1.92(1.44-2.54)$ & $<.001$ & $2.46(1.75-3.45)$ & $<.001$ \\
$\quad$ Korea & $77(4.2)$ & $1.21(0.75-1.94)$ & .443 & $1.01(0.49-2.07)$ & .979 \\
Academic major & & & & & \\
$\quad$ Art and literatured & $698(38.5)$ & 1 & & 1 & \\
$\quad \begin{array}{l}\text { Science and technologye } \\
\text { Medicine and health science }\end{array}$ & $404(22.2)$ & $0.69(0.54-0.89)$ & .004 & $0.43(0.31-0.59)$ & $<.001$ \\
$\quad$ & $712(39.3)$ & $0.59(0.48-0.73)$ & $<.001$ & $0.64(0.49-0.84)$ & .001 \\
\hline
\end{tabular}

aThe factors adjusted, respectively, in the model are presented in the left column.

b"Agree" included "Strongly agree" and "Agree".

"'Disagree" included "Strongly disagree," "Disagree," and "Neutral."

d"Art and literature" included art, literature, law, business management, economics, and tourism.

e"Science and technology" included civil engineering, computer system engineering, electronic engineering, and architecture.

f"Medicine and health science" included medicine, nutrition and food science, publichealth, and nursing.

from China were more likely $(\mathrm{aOR}=2.46,95 \% \mathrm{CI}=1.75-3.45)$ than their Taiwanese counterparts to agree with the potential for electricity shortage. Moreover, those students in "science and technology" $(\mathrm{aOR}=0.43,95 \% \mathrm{CI}=0.31-0.59)$ and "medicine and health science" $(\mathrm{aOR}=0.64$, $95 \% \mathrm{CI}=0.49-0.84$ ) had a lower risk perception than those in "arts and literature" when considering potential electricity shortage in the absence of nuclear energy.

\section{Discussion}

The present study aimed to explore the determinants related to the perception and attitude toward nuclear energy. There are several main findings in this study. The results revealed that the respondents' preference for a clear schedule to phase out NPP was statistically associated with gender, country or region, academic major, and PRR of cancer incidence. The opinions on potential electricity shortage if nuclear energy was phased out were associated with geographic and academic majors of the university students.

Gender has previously been identified as an important demographic variable in health risk perception by many researches. There are different explanations by different hypothesis or theory, such as social role, activities, trust, power relations, and social control. ${ }^{15-18}$ In this study, the statistics revealed that higher proportion of female is in support of phasing out NPP on schedule as compared with male. Results of the previous researches have concluded that the female university students should share the same social class and power as that of males, so that the difference in social class between genders could be ignored. Therefore, the researchers tended to 
believe that the female respondents perceived a higher seriousness of technical risk than males because of the social role, as women perceived their risks mainly depending on living condition and daily activities. ${ }^{8,18,19}$

Japanese respondents were comparatively more likely to support a clear schedule to phase out nuclear energy and less likely to perceive the potential for resulting electricity shortage. The present result confirms previous study findings from Japan, which showed that the Japanese were highly concerned with nuclear safety even before the occurrence of Fukushima nuclear disaster. ${ }^{8,20}$ The Fukushima nuclear disaster triggered a change of "post-Fukushima" energy policy in Japan. The nuclear share of electricity production dropped from $29.2 \%$ (2010) to $18.1 \%$ (2011), and further approached zero (2013). ${ }^{21}$

On the other hand, Chinese respondents were more likely than Taiwanese respondents to support the phasing out of NPPs on schedule and also to perceive the potential for resulting electricity shortage. Research in China revealed that the acceptance of nuclear energy is not high among Chinese respondents but they were mainly concerned about the risk that may affect economic development. ${ }^{9}, 22$ Nuclear energy contributed $1.8 \%$ of the electricity production in 2011, which provided 82.6 TWh, and the electricity consumption is highly related to the GDP in China. ${ }^{23}$

Previous Korean research showed that the Korean did not perceive nuclear-related risk as a high risk. ${ }^{24}$ The present research found that the Korean respondents did not have a preferred schedule to phaseout NPP in their country. Nevertheless, the sample size from Korea is too small and the results are not significant.

Perceived relative risk of cancer incidence is another main variable in the present study, which indicated the respondents' health risk perception on nuclear energy. After controlling the other determinants in multivariate logistic regression, the respondents who perceived PRR $>1$ supported phasing out NPP on schedule as compared with the respondents who perceived PRR $\leq 1$. The results indicated that the association between PRR and preferred schedule to phase out NPPs can be useful indices to denote the perception of nuclear energy.

Yet this study has several limitations. First, distance is a key variable in the studies about the perceived risk and concern on nuclear energy. ${ }^{25,26}$ However, the present research did not show significant results in multivariate logistic regression. This might be because of respondents perceiving the scale of distance differently in different countries. Second, age was not found to be significantly associated with preferred schedule to phase out nuclear energy and potential electricity shortage. This may be because the sampling was limited to university students, which provided a narrow range of ages.

The study is a cross-sectional survey that aimed to understand the respondents' perception and concerns on nuclear energy. Thus, causal effect and the direction of relationship could not be identified. Furthermore, the current research focused on university students, who cannot represent the whole population of the country. Besides, the variation between universities should not be neglected. In addition, we believed that the association between academic majors and preferred schedule to phase-out NPP was not confirmed in the Korean sample, with significant effect via univariate analysis but insignificant in multivariate analysis. Last, the reliability of selfreporting could be a potential limitation.

In conclusion, the current study revealed that the respondents' perceived risk toward nuclear energy was associated with gender, country, and PRR of cancer incidence, which was a new index to predict the respondents' perception toward nuclear energy. For the individual with frequent contact of relevant information will tend to have a lower perceived risk. ${ }^{14}$ In our study, respondents studying science, technology, and medicine were observed to have a lower perceived risk compared to those studying art and literature. We hope that the interdisciplinary education in the future can help minimize the information gap between students, and hence, the next generation can have a better and more informed conversation about these risk topics. The results of this study may provide useful information for risk management and risk education regarding nuclear energy policy in the area. 


\section{Appendix}

Distribution of University and Its Nearest Nuclear Power Plant (NPP; With Distance in Kilometers) $)^{a}$

\begin{tabular}{lllc}
\hline \multirow{2}{*}{ Country or Region } & \multicolumn{1}{c}{ University } & \multicolumn{1}{c}{$\begin{array}{c}\text { Nearest NPP, } \\
\text { Distance }(\mathrm{km})\end{array}$} & $\begin{array}{c}\text { NPP Within } \\
30 \mathrm{~km}\end{array}$ \\
\hline China & \multicolumn{1}{c}{ Shenyang Jianzhu University } & Honganhe, 276 & No \\
& Northeastern University & Honganhe, 273 & No \\
Kopan & University of Ryukyus & Lungmen, 602 & No \\
Taiwan & Yonsei University & Uljin, 223 & No \\
& Chang Gung University & Kuosheng, 33 & No \\
& Chang Jung Christian University & Maanshan, 115 & No \\
& Chinese Culture University & Kuosheng, 14 & Yes \\
& Chung Shan Medical University & Kuosheng, 157 & No \\
& National Central University & Chin Shan, 52 & No \\
& National Quemoy University & Fuqing, 159 & No \\
& National Taipei University & Kuosheng, 24 & Yes \\
& National Taipei University of Education & Kuosheng, 23 & Yes \\
& National Taipei University of Technology & Kuosheng, 21 & Yes \\
& Shu-Te University & Maanshan, 97 & No \\
& Taipei Medical University & Kuosheng, 22 & Yes \\
& Taiwan Police College & Kuosheng, 25 & Yes \\
& Tzu Chi University & Lungmen, 121 & No \\
& University of Kang Ning & Maanshan, 137 & No \\
\hline
\end{tabular}

anformation and distance of NPP obtained from Geographic Information System(GIS).

\section{Acknowledgments}

The authors would like to thank Prof Chin-Fen Chen, Prof Albert Li, Prof Jung-De Wang, Prof Kuo-Ying Wang, Dr Ellen Hsu, Dr Cheng-Fung Lu, Dr Lucetta Tsai, Dr Thung-Chiao Tseng, Mr Guo Jia, Dr. June Wang, Mr Wang Yi, Mr Wu Jun-Jie, Mr Zhang Song, Mr Wu Qing-Yan, Mr Zhang Jing, Mr Po-Yu Lin, Ms Hsien-Ping Tung, and their corresponding organizations for their help in data collection in this research.

\section{Authors' Note}

Marco Chi Fong Ieong and Jung-Chun Ho contributed equally to this study.

\section{Declaration of Conflicting Interests}

The author(s) declared no potential conflicts of interest with respect to the research, authorship, and/or publication of this article.

\section{Funding}

The author(s) received no financial support for the research, authorship, and/or publication of this article.

\section{Reference}

1. International Atomic Energy Agency. Power Reactor Information System (PRIS). http://www.iaea.org/ pris/. Accessed June 6, 2013.

2. World Nuclear Association. Nuclear power in the world today. http://www.world-nuclear.org/info/ Current-and-Future-Generation/Nuclear-Power-in-the-World-Today/\#.UIIIX1M9s4I. Accessed April 2012. 
3. World Nuclear Association. Electricity supplied by nuclear energy. http://www.world-nuclear.org/ Nuclear-Basics/Electricity-supplied-by-nuclear-energy/\#.UWKHfpPviSo, Accessed April 8, 2013.

4. Slovic P, Fischhoff B, Lichtenstein S. Why study risk perception. Risk Anal. 1982;2:83-93.

5. Slovic P. Perception of risk. Science. 1987;236:280-285.

6. Slovic P. Perception of risk from radiation. Radiat Prot Dosimetry. 1996;68:165-180.

7. International Atomic Energy Agency. Fukushima nuclear accident update log. http://www.iaea.org/ newscenter/news/2011/fukushima120411.html. Accessed April 8, 2014.

8. Kanda R, Tsuji S, Yonehara H. Perceived risk of nuclear power and other risks during the last 25 years in Japan. Health Phys. 2012;102:384-390.

9. Yu N, Zhang Y, Wang J, et al. Knowledge of and attitude to nuclear power among residents around Tianwan Nuclear Power Plant in Jiangsu of China. Int J Med Sci. 2012;9:361-369.

10. Lee J. A new perspective on severe nuclear accidents. J Radiol Prot. 2012;32:N107-N111.

11. Lee CT, Chang WP, Hu SL. Risk perception toward nuclear power operation: a comparsion between the residents and employees of the Taipower. Paper presented at: Annual Meeting of Society for Risk Analysis;December 3-6, 2000; Crystal City, VA.

12. Hung HC, Wang TW. Determinants and mapping of collective perceptions of technological risk: the case of the second nuclear power plant in Taiwan. Risk Anal. 2011;31:668-683.

13. Ho JC, Kao SF, Wang JD, et al. Risk perception, trust, and factors related to a planned new nuclear power plant in Taiwan after the 2011 Fukushima disaster. J Radiol Prot. 2013;33:773-789.

14. Scherer CW, Cho H. A social network contagion theory of risk perception. Risk Anal. 2003;23: 261-267.

15. Kung YW, Chen SH. Perception of earthquake risk in Taiwan: effects of gender and past earthquake experience. Risk Anal. 2012;32:1535-1546.

16. Butters J, Mann RE, Wickens CM, Boase P. Gender differences and demographic influences in perceived concern for driver safety and support for impaired driving countermeasures. J Safety Res. 2012;43:405-411.

17. Gustafson PE. Gender differences in risk perception: theoretical and methodological perspectives. Risk Anal. 1998;18:805-811.

18. Flynn J, Slovic P, Mertz CK. Gender, race, and perception of environmental health risks. Risk Anal. 1994;14:1101-1108.

19. Whitfield SC, Rosa EA, Dan A, Dietz T. The future of nuclear power: value orientations and risk perception. Risk Anal. 2009;29:425-437.

20. Hinman GW, Rosa EA, Kleinhesselink RR, Lowinger TC. Perceptions of nuclear and other risks in Japan and the United States. Risk Anal. 1993;13:449-455.

21. World Nuclear Association. Nuclear share figures 2002-2012. http://www.world-nuclear.org/info/ Facts-and-Figures/Nuclear-generation-by-country/\#.UZ8UObXviSo. Accessed May 2013.

22. Xie X, Wang M, Xu L. What risks are Chinese people concerned about? Risk Anal. 2003;23:685-695.

23. US Energy Information Administration, Economic growth continues to drive China's growing need for energy. http://www.eia.gov/todayinenergy/detail.cfm?id=8070. Accessed September 21, 2012.

24. Chung JB, Kim HK, Rho SK. Analysis of local acceptance of a radioactive waste disposal facility. Risk Anal. 2008;28:1021-1032.

25. Huppe M, Weber J. Effects of distance, age and sex upon attitudes toward nuclear power plants: an empirical study. Zentralbl Hyg Umweltmed. 1999;202:331-344.

26. Biel A, Dahlstrand U. Risk perception and the location of a repository for spent nuclear fuel. Scand $J$ Psychol. 1995;36:25-36. 